\title{
Physiological and psychological responses to olfactory simulation by Taiwania (Taiwania cryptomerioides) essential oil and the influence of cognitive bias
}

\author{
Chia-Pin $\mathrm{Yu}^{1,2,3 \dagger}$, Wei-Chieh Weng ${ }^{1 \dagger}$, Jittakon Ramanpong ${ }^{1 *} \mathbb{D}$, Chih-Da Wu ${ }^{4,5}$, Ming-Jer Tsai ${ }^{1,2}$ and \\ John D. Spengler ${ }^{3}$
}

\begin{abstract}
Taiwania (Taiwania cryptomerioides) is a valuable raw material in the wood products industry in Taiwan. An empirical study of the physiological and psychological effects of smelling Taiwania contributes to an understanding of the properties of interior wood that could potentially promote the use of wood materials in a healthy living environment. Prior studies have indicated that pre-knowledge of odors can cause cognitive bias and different responses in subjects. Designed to disclose the therapeutic effects of Taiwania's scent and its extension to environmental health promotions, this study aimed to (1) investigate its effects on human health responses by stimulating olfaction, and (2) explore the role of cognitive bias in exposure to the scent of Taiwania. The results showed Taiwania's volatiles had a relaxation effect in reducing the heart rates of participants. Some negative mood states, such as confusion, fatigue, and depression were suppressed. Regarding sensory perceptions, participants reported Taiwania's scent induced greater affective scores of stimulation, excitement, firmness, distinctiveness, activity, and denseness, but a lower feeling of pleasantness. There were significant effects of positive cognitive bias on reducing the anger-hostility feeling of participants, but no effects on physiological responses. Moreover, the positive information bias alleviated the unpleasantness toward the smell.
\end{abstract}

Keywords: Wooden material, Essential oil, Cognitive bias, Odor, Physiological effects, Psychological effects, Taiwania

\section{Introduction}

Wood construction materials have been employed since ancient times [1] and continually utilized until now as a bio-based construction material [2] especially in modern building that sustainable construction materials have been promoting [3]. At the same time, empirical studies have demonstrated that sensory contact with natural wood and wooden materials induces physiological

*Correspondence: d06625005@ntu.edu.tw

${ }^{\dagger}$ Chia-Pin Yu and Wei-Chieh Weng contributed equally to this work

1 School of Forestry and Resource Conservation, National Taiwan

University, Taipei, Taiwan, ROC

Full list of author information is available at the end of the article relaxation in human [4]. The non-visual senses are possible pathways for these beneficial effects [5]. Even though smell, in humans, is not as acute as other senses [5], it is crucial for perceiving environmental conditions. Generally, odors are ubiquitous, but vary from place to place (i.e., urban and natural environments) and can affect our sense of well-being [5]. Odors indoors can affect residents' comfort and health [6]. Further Matsubara and Kawai [1] have shown that volatile organic compounds (VOCs) emitted from Japanese cedar walls suppress the activation of sympathetic nervous activity, which would help a person to remain physiologically relaxed even in a stressful situation, resulting in that person experiencing a pleasant feeling in such an indoor environment. 
Additionally, wooden interior materials from Japanese cedar have the capability to prevent mental health disturbances and to support an optimum living environment [1]. Therefore, wood odor experienced by humans every day whether from a forest, wooden furniture, building material or products of daily use is commonly acknowledged as natural, pleasant and harmonizing connected with a positive effect on human health [7].

In a nature setting, green plants release oxygen $\left(\mathrm{O}_{2}\right)$, as well as VOCs, or volatiles, which are the secondary metabolic products emitted into an atmosphere from aerial plant parts such as leaves, flowers, and buds [8]. In an indoor environment where the aforementioned wood exists as a building material or furniture, plant volatiles can be released from the wood tissues. Additionally, the aromatic essences or essential oils extracted from plants can be sources of volatiles that are utilized in creating an aromatherapy environment $[9,10]$. Typically, essential oils are the products obtained from distillation of plant tissue and can still maintain the characteristic scent of the original plant material [5]. Moreover, using essential oils in creating an aromatherapy environment is an easy, non-invasive, and natural technique for olfactory stimulation [11]. A number of empirical studies have utilized essential oils from various plant species, such as Japanese cypress [12], rose [13], Hiba [14], rosemary [15], and Siberian fir tree [16] in olfactory stimulation. The usage of essential oils as a means to promote human wellbeing has been a practice since ancient times, however, studies are limited of its therapeutic efficacy [17]. Scientific knowledge of the effect wooden olfactory stimulation has on humans has only recently been explored [4]. Therefore, in order to create a healthy indoor environment, particularly from an olfactory perspective, further research is needed to clarify human responses to woodderived materials.

In Taiwan, Taiwania (Taiwania cryptomerioides) is an endemic tree species that is important in the commercial logging and plantation industries $[18,19]$. Over the past few years the management of this species' plantation has continuously been a priority because of the importance of its large-diameter logs to the wood industry [20]. This relict conifer species possesses the excellent characteristics of being anti-fungal, decay-resistant, and insect-resistant [21]. Also, Taiwania is regarded as one of the most precious building materials because of its excellent durability [22] and the unique yellowish-red color with purplish-pink streaks in its heartwood which offers a sense of good fortune in Taiwanese culture [19]. Recently the chemical composition of its essential oil was determined, with its major components being $\alpha$-cadinol, ferruginol, and $\beta$-eudesmol, each of which exhibits the properties of being antimicrobial and resistant to decay resulting from fungal activity [23]. Especially, $\alpha$-cadinol was the most abundant compound accounted for $16.74 \%$ of all constituents [19]. However, the effects on human physiology and psychology of volatiles emitted from its wood tissue or oil are not well understood. Further, an empirical study of the therapeutic effects on humans of smelling Taiwania will contribute to an understanding of the properties of interior wood, which, from a healthy living environment perspective, could potentially promote the use of wood materials in building construction and decoration. Therefore, elucidation of the physiological and psychological health effects of Taiwania' scent may contribute to the domestic forestry industry via an increase in the awareness of Taiwania's health effects that could potentially increase demand from the public.

Prior studies have indicated that pre-knowledge of odors can cause cognitive bias and different responses in subjects. The concept of mindset has been integrated in olfactory stimulation studies and psychological bias has been proven to be a significant factor in the subjective evaluation of building materials odors [6]. More specifically, Yamanaka et al. [6] stated that people who were informed in advance of the name of a smell were more likely to feel strongly about that scent than people who were not informed. Thus, the responses to an odor can be modulated by influencing the expectations, attitudes, and beliefs of people about the odor [24]. Empirical studies have focused on the alteration effect of cognitive bias on human olfactory perception; for instance, De Araujo et al. [25] reported that people felt significantly more pleasant when smelling clean air that was labeled as "cheddar cheese" as compared to the same air that was labeled as "body odor". Nordin et al. [26] learned that the same volatile substance (i.e., $n$-butanol) was rated as more unpleasant by a group of people who had read negative information about the substance than by another group who had read positive information. Further, the negative information group had a lower number of correct calculations in a given cognitive task than did the positive information group. This evidence provides support for the notion that pre-information about an odor affects the responses of people and results in biases in their odor evaluations that in turn influence their psychological and physiological responses [6]. In the current study, we were concerned with the moderating role cognitive bias may have in distorting the physiological and psychological responses to Taiwania's scent, therefore the study design involved an information cue to control the typical sources of these biased responses.

Specifically, the aims of this study were to (1) investigate the effects on human health responses of Taiwania's volatiles by stimulating olfaction via Taiwania cryptomerioides stem oil, doing so specifically through the lens of 
the scent as a characteristic of wood products, and (2) reveal the influence of cognitive bias in exposure to the scent of Taiwania stem oil on human health outcomes. The first research aim can contribute to the understanding of therapeutic (i.e., physiological and psychological) effects of Taiwania's scent. Meanwhile the second aim will benefit the extension of using woody smell or woodderived smells in environmental health promotions, especially in emotional well-being.

\section{Materials and methods}

\section{Olfactory stimuli}

Taiwania stem oil (experiment) and normal air (control) were implemented in this study as the sources of olfactory stimulation. The essential oil was prepared by the Experimental Forest, National Taiwan University and was extracted via a steam distillation method over six hours with three repetitions. In order to deliver the same concentration and intensity of scent for each subject, the scented and odorless airs were administered using the process illustrated in Fig. 1. With slight modifications, the design of the device followed the best practices of Jo et al.s study [27]. For each experiment, $10 \mu \mathrm{l}$ of Taiwania stem oil were applied to a small piece of odorless tissue paper $(5 \times 5 \mathrm{~cm})$ which was put into a polypropylene bag, which was then filled via an air pump with $12 \mathrm{~L}$ of normal odorless air. The stem oil was allowed to diffuse naturally within the bag for an hour before the experiment began. Additionally, in the experiment the concentration of volatiles was assumed to be the same between subjects. The normal air was prepared the same way as the described process except there was no essential oil added.

\section{Information cues as cognitive bias}

In order to determine the influence of cognitive bias, we randomly assigned the participants into two groups, hinted (positive cue) and non-hinted (neutral cue). In the hinted group, expectations of positive benefits of forest VOCs were established in the participants by reading to them a short essay that disclosed scientific proof on the benefits of nature scents on human bodies. The essay included sentences such as, "nowadays, huge amount of studies has shown the benefits of natural environments on human health. Compared with urban environments, natural environments help people recover from fatigue and have more positive affect on human health" and "many studies have proved that smell of forest environments (such as phytocides released from trees) are beneficial to our physical and mental health" (for the entire essay, please see Additional file 1). While we made sure that the hinted group was "hinted", we did not provide the non-hinted group with any reading materials. In fact, at the beginning of the test when participants were informed of the steps of the experiment, the information cue was not mentioned beforehand to the non-hinted group in case the participants would become self-conscious, which would affect the outcomes.

\section{Participants and experimental procedure}

The experiment was conducted during January 2019 between 8 am and $5 \mathrm{pm}$ at the laboratory of the School of Forestry and Resource Conservation at National Taiwan University, where temperature and humidity were constant during the experiment at $20^{\circ} \mathrm{C}$ and $60 \%$, respectively. A total of 40 healthy participants (16 male and 24

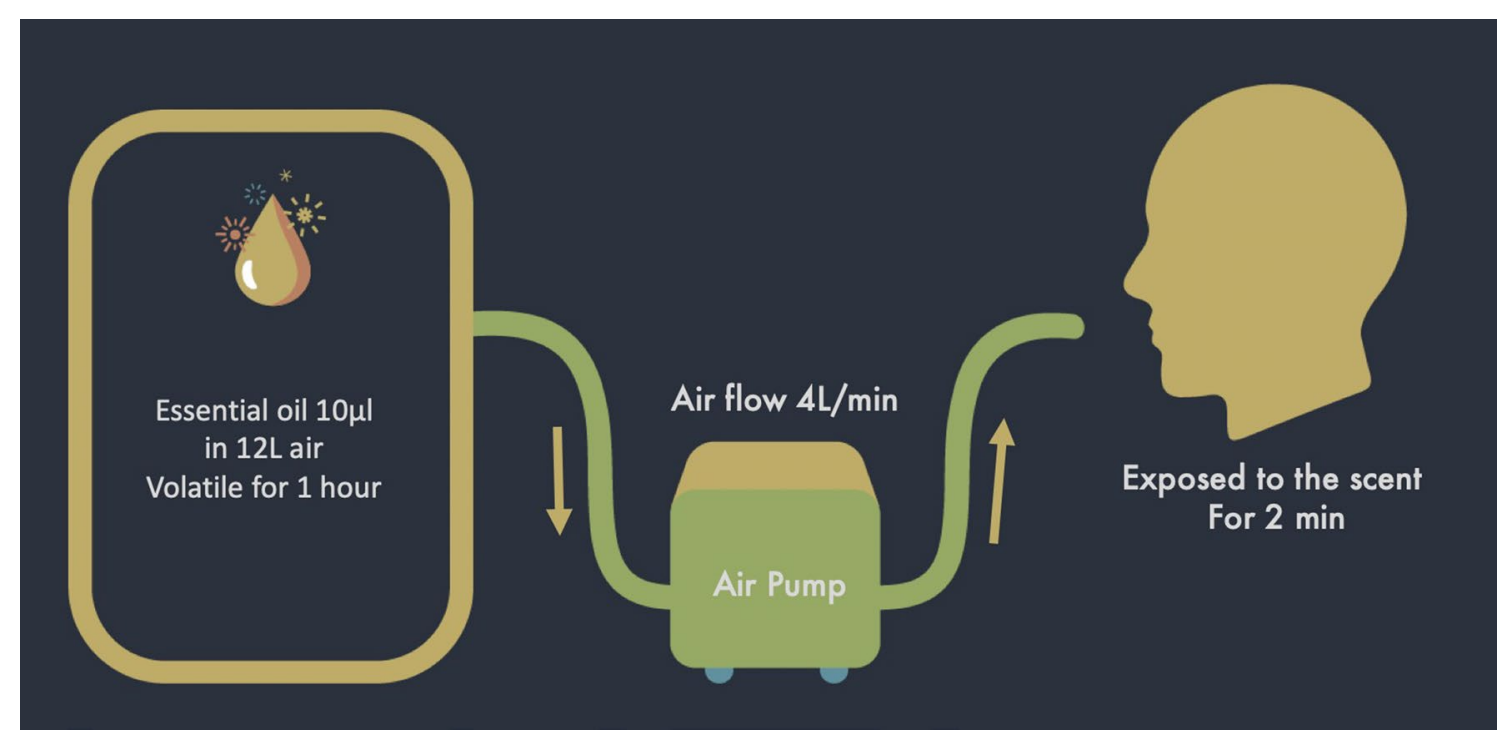

Fig. 1 Olfactory simulation 
female) were voluntarily recruited using social media (i.e., Facebook). They were screened for tobacco use, asthma, symptoms of the common cold, and various breathing disorders. The day before the experiment participants were advised to get enough sleep, roughly $7-8 \mathrm{~h}$, abstain from drinking alcohol or coffee, and not wear any perfume, cologne, or deodorant while participating in the experiment. Participants were randomly divided into two groups: the hinted group $(n=22)$ and the nonhinted group $(n=18)$. All participants were scheduled to attend the experiment individually and the experiment took approximately $30 \mathrm{~min}$ to complete (Fig. 2). On the day of the experiment the planned activities were briefly explained to all participants and informed consent was obtained according to the regulation and the ethical standards of the Research Ethics Committee of National Taiwan University (NTU). After explaining the entire process of the experiment to each participant, the physiological measurement device was attached to each subject included three sensors on the chest and one sensor at the index finger of the left hand in order to measure heart rate (HR), systolic blood pressure (SBP), diastolic blood pressure (DBP), heart rate variability (HRV), and, while they were in a sitting position, an air-blowing device was fixed under each participant's nose at a distance of about $15 \mathrm{~cm}$. After the preparation period, each participant was presented with a constant speed of normal air at $4 \mathrm{~L} / \mathrm{min}$ pumped from the prepared odorless air bag for $2 \mathrm{~min}$. All participants were asked to close their eyes and breathe normally with a closed mouth so that physiological responses could be measured during this time. Immediately afterwards, salivary alpha-amylase (sAA) was collected and questionnaires on semantic differential (SD) methods [27] and Profile of Mood States (POMS) were distributed and completed for the first measurement period. The first measurement period was designed to establish baseline data for each subject. Next, within $3 \mathrm{~min}$ of the intervention period, participants assigned to the non-hinted group were asked to rest in a seated position and to be silent. On the other hand, the participants of the hinted group were fed a positive information bias via a short essay with references attached so as to increase the credibility of the given information. Thereafter, in the first 2 min of the second measurement stage, the odor bag filled with Taiwania's essential oil volatiles was administered to the participants along with the same physiological response measurements and questionnaires as the first measurement period. Throughout the entire process, no participants were ever informed whether the administered air was normal air or Taiwania's oil volatiles. However, one participant in the hinted group was excluded from analysis due to incomplete data of physiological measurements. Therefore, there were 39 participants included in data analysis, with 21 subjects and 18 subjects allocated to the hinted group and non-hinted group, respectively. The ages of participants ranged from 20 to 56 years old, with an average of 28.5 years. Descriptive analyses of the hinted and non-hinted groups are presented in Table 1. However, due to limited number of participants and the concerning of influences of age, gender and women menstrual cycle, Levene's test of equality of error variance was analyzed to clarify their impacts formally in baseline data from the first measurement. Levene's homogeneity test revealed that the variance for all physiological responses were equal across gender and age groups except HF value that did not had homogeneous variance between male and female $(p=0.013)$. For POMS responses, Levene's homogeneity test revealed that the variance for all responses were equal across gender except in anger-hostility subscale $(p=0.011)$, whereas the variance among age groups were not equal in fatigue $(p=0.025)$, tension-anxiety $(p=0.031)$, and depression subscale $(p=0.019)$.

\section{Measures \\ Physiological measurement}

In order to estimate the physiological responses of participants, QHRV (Medeia Ltd. Bulgaria) was used to collect cardiovascular data such as HR, SBP, DBP, and HRV with a sampling rate of $200 \mathrm{~Hz}$. HRV can be used as an

\begin{tabular}{|c|c|c|c|c|c|c|}
\hline \multirow{3}{*}{$\begin{array}{c}\text { Preparation } \\
\text { Introduction and } \\
\text { Install devices }\end{array}$} & \multicolumn{2}{|c|}{ First measurement } & \multirow{3}{*}{$\begin{array}{c}\text { Intervention } \\
\frac{\text { Hinted group: }}{\text { read the text }} \\
\frac{\text { Non-hinted group: }}{\text { rest }}\end{array}$} & \multicolumn{2}{|c|}{ Second measurement } & \multirow{3}{*}{$\begin{array}{l}\text { Wrap-up } \\
\\
\text { Remove the } \\
\text { physiological } \\
\text { electrodes }\end{array}$} \\
\hline & $\begin{array}{l}\text { HR } \\
\text { SBP } \\
\text { DBP } \\
\text { HRV } \\
\end{array}$ & \multirow{2}{*}{$\begin{array}{l}\text { sAA } \\
\text { SD } \\
\text { POMS }\end{array}$} & & $\begin{array}{l}\text { HR } \\
\text { SBP } \\
\text { DBP } \\
\text { HRV } \\
\end{array}$ & \multirow{2}{*}{$\begin{array}{c}\text { SAA } \\
\text { SD } \\
\text { POMS }\end{array}$} & \\
\hline & $\begin{array}{l}\text { Exposure to } \\
\text { normal air }\end{array}$ & & & $\begin{array}{l}\text { Exposure to } \\
\text { Taiwania oil } \\
\text { odor }\end{array}$ & & \\
\hline $\begin{array}{l}10 \mathrm{~min} \\
\text { Fig. } 2 \text { Experimental design }\end{array}$ & $2 \min$ & $5 \mathrm{~min}$ & $3 \mathrm{~min}$ & $2 \min$ & $5 \mathrm{~min}$ & $3 \mathrm{~min}$ \\
\hline
\end{tabular}


Table 1 Description of participants' profiles

\begin{tabular}{|c|c|c|c|c|c|c|}
\hline Variable & $N$ & (\%) & Hinted group & (\%) & Non-hinted group & (\%) \\
\hline \multicolumn{7}{|l|}{ Age group } \\
\hline 20-24 years & 15 & $(38.5)$ & 7 & (33.3) & 8 & $(44.4)$ \\
\hline $25-29$ years & 13 & (33.3) & 8 & $(38.1)$ & 5 & $(27.8)$ \\
\hline 30-34 years & 4 & $(10.3)$ & 1 & $(4.8)$ & 3 & $(16.7)$ \\
\hline$>35$ years & 7 & $(17.9)$ & 5 & $(23.8)$ & 2 & $(11.1)$ \\
\hline \multicolumn{7}{|l|}{ Sex } \\
\hline Male & 16 & $(41.0)$ & 9 & $(42.9)$ & 7 & $(38.9)$ \\
\hline Female & 23 & $(59.0)$ & 12 & $(57.1)$ & 11 & $(61.1)$ \\
\hline Total participants & 39 & $(100.0)$ & 21 & $(100.0)$ & 18 & $(100.0)$ \\
\hline
\end{tabular}

indicator for the activity of the autonomic nervous system, which includes sympathetic nervous system activity and parasympathetic nervous system activity. The power levels of low frequency (LF: 0.04-0.15 Hz) and high frequency (HF: $0.15-0.4 \mathrm{~Hz}$ ) were calculated using the maximum entropy method. HF is regarded as an indicator of parasympathetic nervous system activity, while LF/HF ratio represents sympathetic nervous system activity [28]. In general, reaction to stress, whether physical or psychological, results in activation of sympathetic nervous system activity, which is associated with increased heart rate and blood pressure, along with suppression of parasympathetic nervous system activity [29]. Nipro Salivary Amylase Monitor (Nipro Corp, Japan) was used to detect the concentrations of amylase in the saliva of participants since the presence of amylase indicates a stress state [30].

\section{Psychological measurement}

Two questionnaires were administrated for evaluation of participants' psychological responses to the olfactory stimuli. To assess the change in emotion before and after the exposure to the Taiwania stem oil scent, participants were asked to complete the POMS questionnaire to self-report their current mood state [31]. Each description was rated on 5-point Likert-type scale ranging from "not at all" to "extremely". Further, the SD questionnaire was applied to investigate the impressions of participants based on their subjective perceptions of the odors [27]. Fifteen pairs of contradictory terms were used to describe the smells, including Artificial/Natural, Unrefreshing/Refreshing, Non-woody/Woody and Bland/ Dense, and were rated by participants on a list of sevenpoint scales $(1-7)$.

\section{Data analysis}

All data were compiled, coded, and analyzed using SPSS Statistics 22 (IBM Corporation, NY, USA). The statistical approach involved descriptive statistics, paired sample $t$-tests, and independent $t$-tests. Specifically, in response to the first research intention aiming to investigate the effects of Taiwania's volatiles, paired sample $t$-tests were used to compare both the physiological and psychological response data of the essential oil volatiles with those of the normal air. To answer the second objective intending to explore the role of cognitive bias in odor exposure, independent sample $t$-tests were used to compare the changes in responses between the hinted group and the non-hinted group. $p$-values $<0.05$ were considered statistically significant.

\section{Results}

\section{Effects of Taiwania oil volatiles and cognitive bias on human physiology}

The means and standard deviations for physiological responses of all subjects, the hinted group, and the non-hinted group are presented in Table 2.

The comparisons of Taiwania oil volatiles (experiment) and normal air (control) on human physiological indicators are presented in Table 2. The results indicate that the mean heart rate of all participants decreased significantly $(p<0.05)$ from 81.08 to $79.51 \mathrm{Bpm}$ after inhalation of Taiwania oil volatiles. However, significant differences were not observed for any other physiological variables tested in all participants, the non-hinted group, or the hinted group.

Further comparisons regarding physiological changes between the hinted group and the non-hinted group 
Table 2 Results of physiological responses in all subjects, and both subgroups of interventions

\begin{tabular}{|c|c|c|c|c|}
\hline & Normal air (mean \pm SD) & $\begin{array}{l}\text { Taiwania oil volatiles } \\
\text { (mean } \pm \text { SD) }\end{array}$ & $t$ & $p$ \\
\hline \multicolumn{5}{|c|}{ All subjects $(n=39)$} \\
\hline HR (Bpm) & $81.08 \pm 10.63$ & $79.51 \pm 11.17$ & 2.170 & $0.036^{*}$ \\
\hline $\mathrm{SBP}(\mathrm{mmHg})$ & $99.18 \pm 9.72$ & $99.16 \pm 9.75$ & 0.029 & 0.977 \\
\hline $\mathrm{DBP}(\mathrm{mmHg})$ & $73.08 \pm 7.12$ & $73.03 \pm 7.14$ & 0.172 & 0.865 \\
\hline LF/HF & $1.34 \pm 0.62$ & $1.32 \pm 0.70$ & 0.255 & 0.800 \\
\hline $\mathrm{HF}\left(\mathrm{ms}^{2}\right)$ & $181.66 \pm 97.64$ & $204.97 \pm 161.97$ & -1.090 & 0.283 \\
\hline sAA (kIU/L) & $16.87 \pm 9.56$ & $15.72 \pm 8.77$ & 0.759 & 0.453 \\
\hline \multicolumn{5}{|c|}{ Hinted group $(n=21)$} \\
\hline HR (Bpm) & $82.29 \pm 8.85$ & $79.95 \pm 9.11$ & 2.020 & 0.057 \\
\hline $\mathrm{SBP}(\mathrm{mmHg})$ & $99.39 \pm 7.81$ & $99.43 \pm 7.66$ & -0.028 & 0.978 \\
\hline $\mathrm{DBP}(\mathrm{mmHg})$ & $71.70 \pm 5.15$ & $71.85 \pm 4.90$ & -0.307 & 0.762 \\
\hline LF/HF & $1.48 \pm 0.734$ & $1.36 \pm 0.71$ & 0.961 & 0.348 \\
\hline $\mathrm{HF}\left(\mathrm{ms}^{2}\right)$ & $173.86 \pm 105.35$ & $189.30 \pm 125.48$ & -0.601 & 0.555 \\
\hline sAA (kIU/L) & $17.33 \pm 9.97$ & $18.57 \pm 8.80$ & -0.827 & 0.418 \\
\hline \multicolumn{5}{|c|}{ Non-hinted group $(n=18)$} \\
\hline HR (Bpm) & $79.67 \pm 12.52$ & $79.00 \pm 13.43$ & 0.864 & 0.399 \\
\hline $\mathrm{SBP}(\mathrm{mmHg})$ & $98.93 \pm 11.80$ & $98.85 \pm 11.97$ & 0.134 & 0.895 \\
\hline $\mathrm{DBP}(\mathrm{mmHg})$ & $74.70 \pm 8.76$ & $74.40 \pm 9.05$ & 0.609 & 0.550 \\
\hline $\mathrm{LF} / \mathrm{HF}$ & $1.18 \pm 0.42$ & $1.27 \pm 0.71$ & -0.642 & 0.530 \\
\hline $\mathrm{HF}\left(\mathrm{ms}^{2}\right)$ & $190.75 \pm 89.96$ & $223.25 \pm 198.64$ & -0.901 & 0.380 \\
\hline sAA (kIU/L) & $16.33 \pm 9.31$ & $12.39 \pm 7.69$ & 1.463 & 0.162 \\
\hline
\end{tabular}

$H R$ heart rate, $S B P$ systolic blood pressure, $D B P$ diastolic blood pressure, $L F$ low-frequency power of heart rate variability, $H F$ high-frequency power of heart rate variability, $s A A$ salivary alpha-amylase

${ }^{*} p<0.05$

Table 3 Results of physiological response changes between both subgroups of interventions

\begin{tabular}{|c|c|c|c|c|c|c|}
\hline Physiological changes & Group & $N$ & Mean \pm SD & Change (\%) & $t$ & $p$ \\
\hline \multirow[t]{2}{*}{$\triangle H R(B p m)$} & Non-hinted & 18 & $-0.67 \pm 3.27$ & -0.84 & 1.158 & 0.254 \\
\hline & Hinted & 21 & $-2.33 \pm 5.29$ & -2.88 & & \\
\hline \multirow[t]{2}{*}{$\triangle \mathrm{SBP}(\mathrm{mmHg})$} & Non-hinted & 18 & $-0.084 \pm 2.67$ & -0.08 & -0.086 & 0.932 \\
\hline & Hinted & 21 & $0.034 \pm 5.66$ & 0.04 & & \\
\hline \multirow[t]{2}{*}{$\triangle \mathrm{DBP}(\mathrm{mmHg})$} & Non-hinted & 18 & $-0.30 \pm 2.07$ & -0.40 & -0.648 & 0.521 \\
\hline & Hinted & 21 & $0.15 \pm 2.19$ & 0.21 & & \\
\hline \multirow[t]{2}{*}{$\triangle \mathrm{LF} / \mathrm{HF}$} & Non-hinted & 18 & $0.08 \pm 0.59$ & 7.63 & 1.123 & 0.269 \\
\hline & Hinted & 21 & $-0.12 \pm 0.58$ & -8.11 & & \\
\hline \multirow[t]{2}{*}{$\triangle H F\left(m^{2}\right)$} & Non-hinted & 18 & $32.49 \pm 152.99$ & 17.04 & 0.393 & 0.696 \\
\hline & Hinted & 21 & $15.44 \pm 117.69$ & 8.88 & & \\
\hline \multirow[t]{2}{*}{$\triangle s A A(k \mid \cup / L)$} & Non-hinted & 18 & $-3.94 \pm 11.44$ & -24.13 & -1.744 & 0.089 \\
\hline & Hinted & 21 & $1.24 \pm 6.86$ & 7.16 & & \\
\hline
\end{tabular}

$\Delta=$ posttest - pretest

were examined (Table 3). The results demonstrate that the effects of cognitive biases on human physiological indicators were not significantly different. The findings indicate that the alteration of physiological responses resulting from the hinted intervention were similar to the responses caused by the non-hinted intervention.

\section{Effects of Taiwania oil volatiles and cognitive biases} on emotional state

The effects of Taiwania oil volatiles on emotional state indicators in all subjects, the hinted group, and the non-hinted group are presented in Table 4. 
Table 4 Results of POMS responses in all subjects and the both exposure groups

\begin{tabular}{|c|c|c|c|c|}
\hline & $\begin{array}{l}\text { Normal air } \\
(\text { mean } \pm \text { SD) }\end{array}$ & $\begin{array}{l}\text { Taiwania } \\
\text { oil volatiles } \\
\text { (mean } \pm S D)\end{array}$ & $t$ & $p$ \\
\hline \multicolumn{5}{|c|}{ All subjects $(n=39)$} \\
\hline Confusion & $0.91 \pm 0.76$ & $0.58 \pm 0.62$ & 3.974 & $<0.001^{* * *}$ \\
\hline Vigor & $1.37 \pm 0.89$ & $1.17 \pm 0.99$ & 1.928 & 0.061 \\
\hline Fatigue & $0.81 \pm 0.91$ & $0.49 \pm 0.70$ & 3.610 & $0.001^{* * *}$ \\
\hline $\begin{array}{l}\text { Anger-hos- } \\
\text { tility }\end{array}$ & $0.14 \pm 0.19$ & $0.10 \pm 0.25$ & 0.884 & 0.382 \\
\hline $\begin{array}{l}\text { Tension- } \\
\text { anxiety }\end{array}$ & $0.58 \pm 0.75$ & $0.42 \pm 0.64$ & 1.826 & 0.076 \\
\hline Depression & $0.30 \pm 0.50$ & $0.17 \pm 0.35$ & 3.401 & $0.002^{* *}$ \\
\hline \multicolumn{5}{|c|}{ Hinted group $(n=21)$} \\
\hline Confusion & $0.86 \pm 0.68$ & $0.55 \pm 0.59$ & 3.016 & $0.007^{* *}$ \\
\hline Vigor & $1.52 \pm 0.88$ & $1.39 \pm 1.01$ & 1.041 & 0.310 \\
\hline Fatigue & $0.83 \pm 0.88$ & $0.48 \pm 0.53$ & 2.469 & $0.023^{*}$ \\
\hline $\begin{array}{l}\text { Anger-hos- } \\
\text { tility }\end{array}$ & $0.18 \pm 0.20$ & $0.03 \pm 0.10$ & 3.167 & $0.005^{* *}$ \\
\hline $\begin{array}{l}\text { Tension- } \\
\text { anxiety }\end{array}$ & $0.55 \pm 0.70$ & $0.31 \pm 0.63$ & 2.308 & $0.032^{*}$ \\
\hline Depression & $0.28 \pm 0.49$ & $0.12 \pm 0.34$ & 2.941 & $0.008^{* *}$ \\
\hline \multicolumn{5}{|c|}{ Non-hinted group $(n=18)$} \\
\hline Confusion & $0.98 \pm 0.87$ & $0.61 \pm 0.66$ & 2.597 & $0.019^{*}$ \\
\hline Vigor & $1.19 \pm 0.89$ & $0.91 \pm 0.92$ & 1.637 & 0.120 \\
\hline Fatigue & $0.79 \pm 0.97$ & $0.51 \pm 0.88$ & 2.858 & $0.011^{*}$ \\
\hline $\begin{array}{l}\text { Anger-hos- } \\
\text { tility }\end{array}$ & $0.10 \pm 0.16$ & $0.18 \pm 0.35$ & -1.064 & 0.302 \\
\hline $\begin{array}{l}\text { Tension- } \\
\text { anxiety }\end{array}$ & $0.61 \pm 0.82$ & $0.54 \pm 0.65$ & 0.487 & 0.633 \\
\hline Depression & $0.32 \pm 0.52$ & $0.22 \pm 0.37$ & 1.784 & 0.092 \\
\hline
\end{tabular}

Across all participants emotional state indicators decreased (improved) when smelling Taiwania volatiles. Changes reached significance for the indicators of confusion $(p<0.001)$, fatigue $(p<0.001)$, and depression $(p<0.01)$. The mean score for these negative mood subscales indicates significant decreases after exposure to the scent of Taiwania essential oil.

In the hinted group, there were significant differences in confusion $(p<0.05)$, fatigue $(p<0.05)$, anger-hostility $(p<0.01)$, tension-anxiety $(p<0.05)$, and depression $(p<0.01)$. For the non-hinted group, the significant differences were found for confusion $(p<0.05)$ and fatigue $(p<0.05)$. These negative mood subscales for both subgroups also revealed a lower score after exposure to the scent of Taiwania essential oil.

Comparisons regarding mood state changes between the hinted group and the non-hinted group were examined (Table 5). The only significant difference after inhalation of Taiwania oil volatiles between the hinted group and the non-hinted group was observed in the angerhostility subscale. The hinted group had an anger-hostility level that was $83 \%$ lower after inhaling Taiwania odor, whereas the non-hinted group had an anger-hostility level that was $80 \%$ higher.

\section{Effects of Taiwania oil volatiles and cognitive bias on subjective perceptions}

Figure 3 illustrates and compares the subjective feelings of participants after having breathed the normal air and Taiwania oil volatiles. After inhalation of the Taiwania essential oil, all participants rated levels significantly higher in 6 out of 15 groups of adjectives as

Table 5 Results of psychological response changes between two groups of interventions

\begin{tabular}{|c|c|c|c|c|c|c|}
\hline Psychological changes & Group & $N$ & Mean \pm SD & Change (\%) & $t$ & $p$ \\
\hline \multirow[t]{2}{*}{$\triangle$ Confusion } & Non-hinted & 18 & $-0.37 \pm 0.60$ & -37.76 & -0.364 & 0.718 \\
\hline & Hinted & 21 & $-0.30 \pm 0.46$ & -36.05 & & \\
\hline \multirow[t]{2}{*}{$\triangle$ Vigor } & Non-hinted & 18 & $-0.28 \pm 0.72$ & -23.53 & -0.670 & 0.507 \\
\hline & Hinted & 21 & $-0.14 \pm 0.60$ & -8.55 & & \\
\hline \multirow[t]{2}{*}{$\triangle$ Fatigue } & Non-hinted & 18 & $-0.28 \pm 0.41$ & -35.44 & 0.418 & 0.679 \\
\hline & Hinted & 21 & $-0.35 \pm 0.65$ & -42.17 & & \\
\hline \multirow[t]{2}{*}{$\triangle$ Anger-hostility } & Non-hinted & 18 & $0.08 \pm 0.32$ & 80.00 & 2.627 & $0.012^{* *}$ \\
\hline & Hinted & 21 & $-0.14 \pm 0.21$ & -83.33 & & \\
\hline \multirow[t]{2}{*}{$\triangle$ Tension-anxiety } & Non-hinted & 18 & $-0.07 \pm 0.64$ & -11.48 & 0.924 & 0.362 \\
\hline & Hinted & 21 & $-0.24 \pm 0.47$ & -43.64 & & \\
\hline \multirow[t]{2}{*}{$\triangle$ Depression } & Non-hinted & 18 & $-0.10 \pm 0.23$ & -31.25 & 0.744 & 0.462 \\
\hline & Hinted & 21 & $-0.16 \pm 0.24$ & -57.17 & & \\
\hline
\end{tabular}

$\Delta=$ posttest - pretest; ${ }^{* *} p<0.01$ 


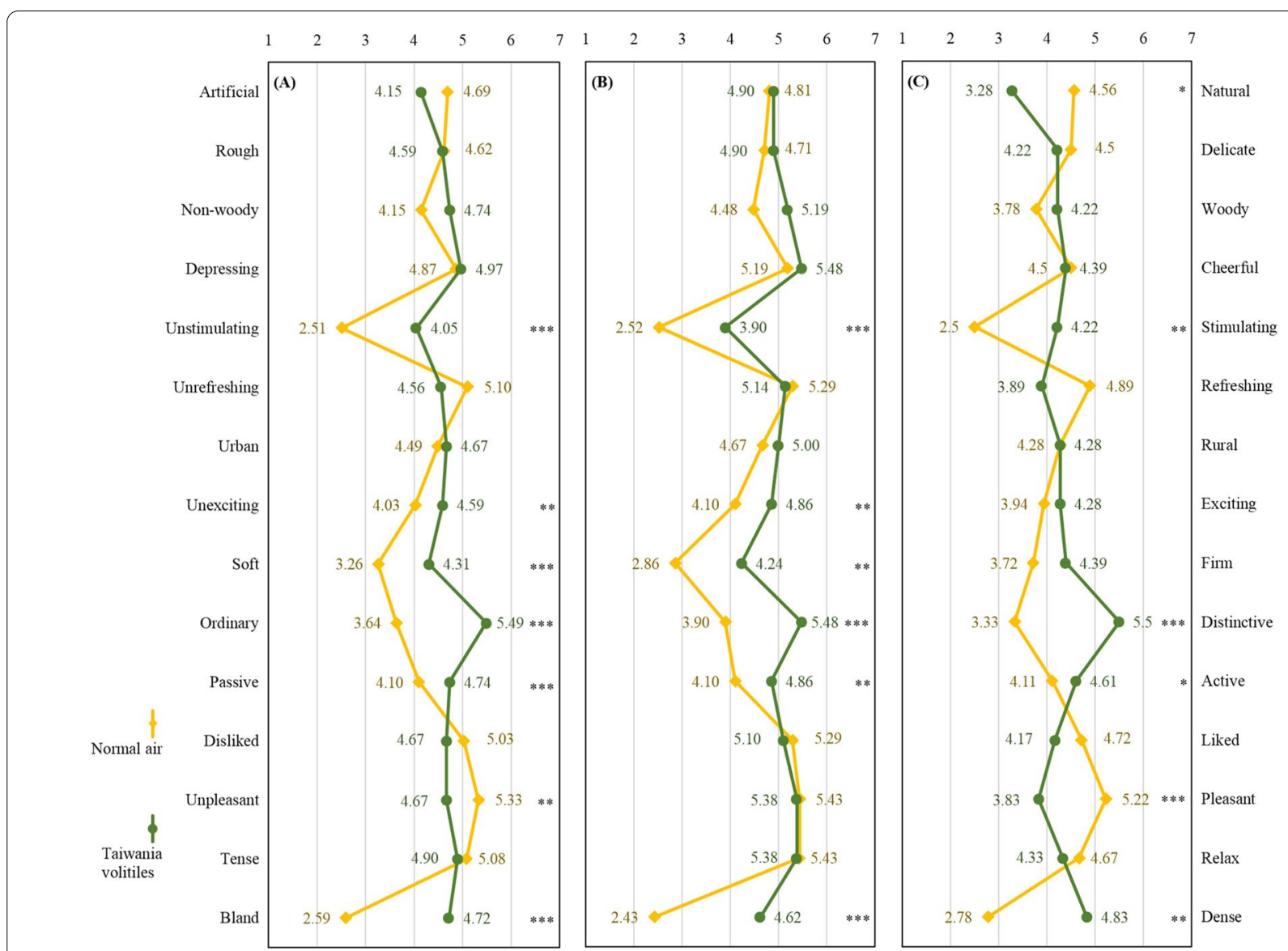

Fig. 3 Polarity profiles of the semantic differential score with the results of pair sample $t$ test. A All subjects, $n=39, \mathbf{B}$ hinted group, $n=21$, and $\mathbf{C}$ non-hinted group, $n=18,{ }^{*} p<0.05,{ }^{* *} p<0.01,{ }^{* * *} p<0.001$

compared to after normal air inhalation. These groups included "unstimulating-stimulating" $(p<0.001)$, "unexciting-exciting" $(p<0.01)$, "soft-firm" $(p<0.001)$, "ordinary-distinctive" $(p<0.001)$, "passive-active" $(p<0.001)$, and "bland-dense" $(p<0.001)$. Additionally, participants rated scores significantly lower for "unpleasant-pleasant" $(p<0.01)$ (see Fig. 3A).

When the participants were separated into the two information bias interventions, we found significant differences existed in "unstimulating-stimulating" $(p<0.001)$, "unexciting-exciting" $(p<0.01)$, "soft-firm" $(p<0.01)$, "ordinary-distinctive" $(p<0.001)$, "passiveactive" $(p<0.01)$, and "bland-dense" $(p<0.001)$ in the hinted group, and significant differences were found in "artificial-natural" $(p<0.05)$, "unstimulating-stimulating" $(p<0.01)$, "ordinary-distinctive" $(p<0.001)$, "passive-active" $(p<0.05)$, "unpleasant-pleasant" $(p<0.001)$, and "bland-dense" $(p<0.01)$ in the non-hinted group. The results of paired sample $t$-testing revealed that the scores for pleasantness $(p<0.001)$ and naturalness $(p<0.05)$ also were lower in the non-hinted group after inhalation of Taiwania oil volatiles. Meanwhile, the hinted group did not exhibit these significant difference for either subscale between exposure to the normal air and Taiwania's scent (see Fig. 3B, C).

Comparisons of the changes in subjective perceptions between the hinted group and the non-hinted group were examined (see Table 6). The only significant difference between the hinted group and the non-hinted group after inhalation of Taiwania oil volatiles was observed for the "unpleasant-pleasant" subscale. The non-hinted group had a pleasant feeling toward the Taiwania scent that was $26 \%$ lower, whereas the hinted group had a pleasant feeling that was only $1 \%$ lower.

\section{Discussion}

In the present study, our data suggest that Taiwania's scent can only suppress heart rate showing that the therapeutic effects of Taiwania volatiles were limited, particularly in physiological responses, compared to findings of other studies that used other plant species (i.e., [12, 31, 32]). Considering the effects of cognitive 
Table 6 Results of semantic differential scale response changes between two groups of interventions

\begin{tabular}{|c|c|c|c|c|c|c|}
\hline Physiological changes & Group & $N$ & Mean \pm SD & Change (\%) & $t$ & $p$ \\
\hline \multirow[t]{2}{*}{$\triangle$ Artificial/natural } & Non-hinted & 18 & $-1.28 \pm 2.35$ & -28.07 & -1.986 & 0.054 \\
\hline & Hinted & 21 & $0.10 \pm 1.97$ & 1.87 & & \\
\hline \multirow[t]{2}{*}{$\triangle$ Rough/delicate } & Non-hinted & 18 & $-0.278 \pm 1.49$ & -6.22 & -0.835 & 0.409 \\
\hline & Hinted & 21 & $0.19 \pm 1.94$ & 4.03 & & \\
\hline \multirow[t]{2}{*}{$\triangle$ Non-woody/woody } & Non-hinted & 18 & $0.44 \pm 2.43$ & 11.64 & -0.352 & 0.727 \\
\hline & Hinted & 21 & $0.71 \pm 2.35$ & 15.85 & & \\
\hline \multirow[t]{2}{*}{$\triangle$ Depressing/cheerful } & Non-hinted & 18 & $-0.11 \pm 2.08$ & -2.44 & -0.680 & 0.501 \\
\hline & Hinted & 21 & $0.29 \pm 1.55$ & 5.59 & & \\
\hline \multirow[t]{2}{*}{$\triangle$ Unstimulating/stimulating } & Non-hinted & 18 & $1.72 \pm 1.93$ & 68.80 & 0.599 & 0.553 \\
\hline & Hinted & 21 & $1.38 \pm 1.63$ & 54.76 & & \\
\hline \multirow[t]{2}{*}{$\triangle$ Unrefreshing/refreshing } & Non-hinted & 18 & $-1.00 \pm 2.14$ & -20.45 & -1.379 & 0.176 \\
\hline & Hinted & 21 & $-0.14 \pm 1.74$ & -2.84 & & \\
\hline \multirow[t]{2}{*}{$\triangle$ Urban/rural } & Non-hinted & 18 & $0.00 \pm 1.50$ & 0.00 & -0.656 & 0.516 \\
\hline & Hinted & 21 & $0.33 \pm 1.65$ & 7.07 & & \\
\hline \multirow[t]{2}{*}{$\triangle$ Unexciting/exciting } & Non-hinted & 18 & $0.33 \pm 1.24$ & 8.63 & -1.174 & 0.248 \\
\hline & Hinted & 21 & $0.76 \pm 1.04$ & 18.54 & & \\
\hline \multirow[t]{2}{*}{$\triangle$ Soft/firm } & Non-hinted & 18 & $0.67 \pm 1.71$ & 18.01 & -1.251 & 0.19 \\
\hline & Hinted & 21 & $1.38 \pm 1.83$ & 48.25 & & \\
\hline \multirow[t]{2}{*}{$\triangle$ Ordinary/distinctive } & Non-hinted & 18 & $2.17 \pm 1.72$ & 65.17 & 1.022 & 0.313 \\
\hline & Hinted & 21 & $1.57 \pm 1.89$ & 40.51 & & \\
\hline \multirow[t]{2}{*}{$\triangle$ Passive/active } & Non-hinted & 18 & $0.50 \pm 0.99$ & 12.17 & -0.745 & 0.461 \\
\hline & Hinted & 21 & $0.76 \pm 1.18$ & 18.54 & & \\
\hline \multirow[t]{2}{*}{$\triangle$ Disliked/liked } & Non-hinted & 18 & $-0.56 \pm 1.42$ & -11.65 & -0.774 & 0.444 \\
\hline & Hinted & 21 & $-0.19 \pm 1.50$ & -3.59 & & \\
\hline \multirow[t]{2}{*}{$\triangle$ Unpleasant/pleasant } & Non-hinted & 18 & $-1.39 \pm 1.42$ & -26.63 & -2.968 & $0.005^{* *}$ \\
\hline & Hinted & 21 & $-0.05 \pm 1.40$ & -0.92 & & \\
\hline \multirow[t]{2}{*}{$\triangle$ Tense/relax } & Non-hinted & 18 & $-0.33 \pm 1.28$ & -7.28 & -0.594 & 0.556 \\
\hline & Hinted & 21 & $-0.05 \pm 1.66$ & -0.92 & & \\
\hline \multirow[t]{2}{*}{$\triangle$ Bland/dense } & Non-hinted & 18 & $2.06 \pm 2.31$ & 73.74 & -0.188 & 0.852 \\
\hline & Hinted & 21 & $2.19 \pm 2.16$ & 90.12 & & \\
\hline
\end{tabular}

$\Delta=$ posttest - pretest; ${ }^{* *} p<0.01$

bias on human physiology, both subgroups revealed no significant difference for any of the physiological variables. Additionally, significant differences in changes of physiological responses resulting from positive information cues (hinted) were similar to the responses caused by neutral cues (non-hinted). This finding indicates the information cues did not influence physiological responses.

For emotional states, significant differences between normal air inhalation and Taiwania volatiles inhalation were observed in confusion, fatigue, and depression for all subjects. Further, we found that there were significant differences in confusion, fatigue, anger-hostility, tension-anxiety, and depression in the hinted group and significant differences in confusion and fatigue in the non-hinted group. In general, subjects perceived an improvement in negative moods after they smelled
Taiwania essential oil. It is clear that olfaction and emotion are intimately associated. Existing literature highlights how scents affect mood [33]. The present findings confirm the general notion that nature scents especially from wood materials have a beneficial effect on human moods and emotions via reducing negative emotion states.

Changes in emotional states were not affected by the information cue, except in the anger-hostility dimension. The results of multiple comparisons between the hinted and non-hinted groups provided a closer look at the data. Interestingly, we found each negative emotion state was improved in the hinted group, but similar results for each were not observed in the non-hinted group, as the nonhinted group had a score $80 \%$ higher for anger-hostility. One explanation for this is that the positive cognitive intervention implemented in the hinted group led to the 
lower level of anger-hostility as compared to level of the non-hinted group. It can be postulated that the positive information cue influences psychological responses and, as a result, participants with the positive information cue had a greater perception of health benefits from Taiwania's odor than did the participants with no information cue. Our findings regarding the effects of cognitive bias are consistent with those in a prior study focusing on odor control in building interiors, that the pre-knowledge about odors emitted from building materials affects the moods of occupants and causes biases in their odor evaluations [6]. These results underscore the importance of conceptually driven approaches in analyzing responses to volatile chemicals, ones that rely heavily on the influence of memories and expectations in the perceptions of scents [34].

With regard to sensory evaluation, it is obvious that Taiwania oil volatiles induce greater feelings of stimulation, excitement, firmness, distinctiveness, activity, unpleasantness, and denseness in all subjects. These results indicate that Taiwania oil odor evoked greater feelings of alertness among participants. Interestingly, even though these feelings of alertness have been reported, there has been no increase in the sympathetic nervous system activity measured in this study. The same situation was reported before in the prior research studied in the Japanese's responses toward Japanese cedar's odor which the authors hypothesized that this unchanging of sympathetic nervous system activity might relate to the human physiological adaptation [35] but there was still no any sound evidences to support this assumption. Our results seem to indicate that Taiwania oil scent is relatively strong in eliciting these feelings which highlights that not every forest-related stimulus has positive effects on physical and mental health. Also, what sort of environmental stimuli are exposed by humans is more important. Our findings are supported by an idea proposed by Song et al. [34], that affective components elicited by scents may be as varied as the differences in VOCs from each tree species. Additionally, the unique components of VOCs emitted from Taiwania oil can create unique subjective feelings in people. However, the influence of cognitive bias can alter the subjective evaluation of naturalness and pleasantness. The positive information cue significantly alleviated the feeling of unpleasantness, which implies positive cues are crucial in creating a comfortable environment. The analysis of change scores supports this notion because they reflect that the effect of the positive information intervention induced the difference in unpleasant-pleasant levels between the groups. This is in line with a prior empirical study of human interaction with an indoor environment that reported that feelings of unpleasantness toward a concrete odor were reduced when participants were told that the odor smelled of cypress [6].

A number of limitations in this study need to be noted. First, exposure to plant-derived volatiles from different plant species (i.e., $[1,8,12,36])$ can have both positive and negative effects on humans and animals [8]. Whereas numerous prior studies have reported the beneficial effects of these scents on physiological variables, those favorable effects were limited in this study. For this reason, additional beneficial effects such as the brain responses of people to Taiwania volatiles should be clarified in future research. Second, while there maybe individual differences in response, overall we did not discern much of a difference in physiological responses between the informed and naive groups. It should be further noted that "concentration" could play an important role in regard to physiological and psychological responses, for example, a pleasant smell could be overwhelming if it is too strong. In this sense, we suggest a future study designs a variety of concentrations for illustrating an optimal outcome. Thirdly, even though the age, gender [37] and women menstrual cycle [38] influences the complexity of HRV, our research was not controlled for these variations because of the limited number of participants. Therefore, the effects of individual differences were averaged in the analysis of comparing subject's responses toward essential oil volatiles and normal air in exploring the therapeutic effects of Taiwania's volatiles. However, these between-subject variabilities were eliminated by the pretest-posttest design and were not included in the analysis of exploring the role of cognitive bias in odor exposure. Lastly, the study was solely conducted with Taiwanese who may have subconscious association with Taiwania odor which may influence psychophysiological responses. Therefore, performing this study with sample populations from a broader range of cultures would increase the study's generalizability.

\section{Conclusions}

In response to the first research objective aiming to investigate the effects of Taiwania's volatiles on human health responses, we found that Taiwania essential oil volatiles had a relaxation effect in reducing the heart rates of participants. It also suppressed some negative mood states, such as confusion, fatigue, and depression. Regarding sensory perceptions, for all participants Taiwania essential oil odor induced greater affective scores of stimulation, excitement, firmness, distinctiveness, activity, and denseness, but a lower feeling of pleasantness. To answer the second research question aiming to explore the influence of cognitive bias in exposure to Taiwania's scent, we found that the information cue had no effect on physiological responses. However, there was a 
significant improvement in anger-hostility between the hinted and non-hinted groups. Unlike subjects who did not receive a cognitive intervention, the group of people who received positive information exhibited in their psychological responses a distinct suppression of the negative anger-hostility mood state. Concerning managerial implications, this research mainly contributes to the wood industry by increasing awareness of the health benefits of Taiwania wood and its essential oil, doing so by providing evidences of healthy living environments, restorative environments and promoting use of these wood as sustainable material. Further, the importance of interpreting information related to wood-derived smells has been highlighted in environmental health promotion measures.

\section{Abbreviations}

VOCs: Volatile organic compounds; $\mathrm{O}_{2}$ : Oxygen; NTU: National Taiwan University; HR: Heart rate; SBP: Systolic blood pressure; DBP: Diastolic blood pressure; HRV: Heart rate variability; sAA: Salivary alpha-amylase; SD: Semantic differential; POMS: Profile of mood states; LF: Low frequency; HF: High frequency.

\section{Supplementary Information}

The online version contains supplementary material available at https://doi. org/10.1186/s10086-022-02021-w.

Additional file 1. Essay: The therapeutic effect of forest scent

\section{Acknowledgements}

The authors express gratitude for all the help from the XNEA staff.

\begin{abstract}
Authors' contributions
Funding acquisition, conceptualization, methodology, supervision, formal analysis, writing — review and editing: YCP. Conceptualization, methodology, data curation, formal analysis, writing—original draft: WWC. Conceptualization, data curation, formal analysis, writing — review and editing: RJ. Supervision, writing — review and editing: WCD. Supervision, writing — review and editing: TMJ. Supervision, writing —review and editing: SJD. All authors read and approved the final manuscript.
\end{abstract}

\section{Funding}

This work was supported by the Ministry of Science and Technology, Taiwan [Grant numbers 108-2410-H-002-185].

\section{Availability of data and materials}

The datasets used and/or analyzed during the current study are available from the corresponding author on reasonable request.

\section{Declarations}

\section{Ethics approval and consent to participate}

Ethical review and approval were obtained according to the regulation and the ethical standards of the Research Ethics Committee of National Taiwan University (NTU) (NTU-REC No. 201607HS008).

\section{Consent for publication}

There are no details on individual participants within the manuscript.

\section{Competing interests}

The authors declare that they have no competing interests.

\section{Author details}

${ }^{1}$ School of Forestry and Resource Conservation, National Taiwan University, Taipei, Taiwan, ROC. ${ }^{2}$ The Experimental Forest, College of Bioresources and Agriculture, National Taiwan University, Nantou, Taiwan, ROC. ${ }^{3}$ Department of Environmental Health, Harvard T.H. Chan School of Public Health, Boston, USA. ${ }^{4}$ Department of Geomatics, National Cheng Kung University, Tainan, Taiwan, ROC. ${ }^{5}$ National Institute of Environmental Health Sciences, National Health Research Institutes, Miaoli, Taiwan, ROC.

Received: 19 October 2021 Accepted: 15 February 2022

Published online: 03 March 2022

\section{References}

1. Matsubara E, Kawai S (2014) VOCs emitted from Japanese cedar (Cryptomeria japonica) interior walls induce physiological relaxation. Build Environ 72:125-130

2. Göswein V, Reichmann J, Habert G, Pittau F (2021) Land availability in Europe for a radical shift toward bio-based construction. Sustain Cities Soc 70:102929

3. Arkar C, Domjan S, Medved S (2018) Lightweight composite timber façade wall with improved thermal response. Sustain Cities Soc 38:325-332

4. Ikei H, Song C, Miyazaki Y (2017) Physiological effects of wood on humans: a review. J Wood Sci 63:1-23

5. Franco LS, Shanahan DF, Fuller RA (2017) A review of the benefits of nature experiences: more than meets the eye. Int J Environ Res Public Health 14:864

6. Yamanaka T, Sagara K, Kotani H, Takemura A, Fujiwara M (2009) Psychological bias caused by notification of odor name in sensory evaluation test of odor. Build Environ 44:1350-1355

7. Schreiner SB, Loos HM (2018) The smell of wood and its impact on physiological responses. Int J Psychophysiol 131:S40

8. LV Y, Li K, Wan J, Li C, Song X (2020) Effects of flower volatiles from two liana species on spontaneous behavior of mice. Shengtai Xuebao/ Acta Ecol Sin 40:90-96

9. Huang H-L, Tsai T-J, Hsu N-Y, Lee C-C, Wu P-C, Su H-J (2012) Effects of essential oils on the formation of formaldehyde and secondary organic aerosols in an aromatherapy environment. Build Environ 57:120-125

10. Cooke B, Ernst E (2000) Aromatherapy: a systematic review. Br J Gen Pract 50:493-496

11. Chen MC, Fang SH, Fang L (2015) The effects of aromatherapy in relieving symptoms related to job stress among nurses. Int J Nurs Pract 21:87-93

12. Ikei H, Song C, Miyazaki Y (2015) Physiological effect of olfactory stimulation by Hinoki cypress (Chamaecyparis obtusa) leaf oil. J Physiol Anthropol 34:44

13. Naziroğlu M, Kozlu S, Yorgancigil E, Uğuz AC, Karakuş K (2013) Rose oil (from Rosa $\times$ damascena Mill.) vapor attenuates depression-induced oxidative toxicity in rat brain. J Nat Med 67:152-158

14. Hiruma T, Yabe H, Sato Y, Sutoh T, Kaneko S (2002) Differential effects of the hiba odor on CNV and MMN. Biol Psychol 61:321-331

15. Nasiri A, Boroomand MM (2021) The effect of rosemary essential oil inhalation on sleepiness and alertness of shift-working nurses: a randomized, controlled field trial. Complement Ther Clin Pract 43:101326

16. Matsubara E, Fukagawa M, Okamoto T, Ohnuki K, Shimizu K, Kondo R (2011) The essential oil of Abies sibirica (Pinaceae) reduces arousal levels after visual display terminal work. Flavour Fragr J 26:204-210

17. Lima NGPB, De Sousa DP, Pimenta FCF, Alves MF, De Souza FS, MacEdo RO, Cardoso RB, De Morais LCSL, Melo Diniz MDFF, De Almeida RN (2013) Anxiolytic-like activity and GC-MS analysis of (R)-(+)-limonene fragrance, a natural compound found in foods and plants. Pharmacol Biochem Behav 103:450-454

18. Chang ST, Wang SY, Kuo YH (2003) Resources and bioactive substances from Taiwania (Taiwania cryptomerioides). J Wood Sci 49:1-4

19. Tsao N-W, Chien S-C, Kuo Y-H, Wang S-Y (2021) Extractives elucidation of Taiwania cryptomerioides sapwood. J Wood Sci 67:16

20. Wang SY, Chiu CM, Lin CJ (2003) Application of the drilling resistance method for annual ring characteristics: evaluation of Taiwania (Taiwania cryptomerioides) trees grown with different thinning and pruning treatments. J Wood Sci 49:116-124 
21. Ma LT, Lee YR, Liu PL, Cheng YT, Shiu TF, Tsao NW, Wang SY, Chu FH (2019) Phylogenetically distant group of terpene synthases participates in cadinene and cedrane-type sesquiterpenes accumulation in Taiwania cryptomerioides. Plant Sci 289:110277

22. Kuo Y-H, Chyu C-F (2003) Two novel sesquiterpenes from the roots of Taiwania cryptomerioides Hayata. Tetrahedron Lett 44:7221-7223

23. Ho CL, Yang SS, Chang TM, Su YC (2012) Composition, antioxidant, antimicrobial and anti-wood-decay fungal activities of the twig essential oil of Taiwania cryptomerioides from Taiwan. Nat Prod Commun 7:261-264

24. Dalton $P$ (2002) Odor, irritation and perception of health risk. Int Arch Occup Environ Health 75:283-290

25. de Araujo IE, Rolls ET, Velazco MI, Margot C, Cayeux I (2005) Cognitive modulation of olfactory processing. Neuron 46:671-679

26. Nordin S, Claeson AS, Andersson M, Sommar L, Andrée J, Lundqvist K, Andersson L (2013) Impact of health-risk perception on odor perception and cognitive performance. Chemosens Percept 6:190-197

27. Jo H, Rodiek S, Fujii E, Miyazaki Y, Park B-J, Ann S-W (2013) Physiological and psychological response to floral scent. HortScience 48:82-88

28. Colombo J, Arora R, DePace NL, Vinik Al (2014) Clinical autonomic dysfunction: measurement, indications, therapies, and outcomes. Springer, Cham

29. Ziegler MG (2004) Psychological stress and the autonomic nervous system. In: Robertson D, Biaggioni I, Burnstock G, Low PA (eds) Prim Auton Nerv Syst, 2nd edn. Elsevier Inc., San Diego, pp 189-190

30. Yamaguchi M, Kanemori T, Kanemaru M, Takai N, Mizuno Y, Yoshida H (2004) Performance evaluation of salivary amylase activity monitor. Biosens Bioelectron 20:491-497

31. Miyazaki Y, Yutaka M, Shigeo K (1992) Changes in mood by inhalation of essential oils in humans II: effect of essential oils on blood pressure, heart rate, RR intervals, performance, sensory evaluation and POMS (in Japanese). Mokuzai Gakkaishi 38:909-913

32. Song C, Ikei H, Miyazaki Y (2019) Physiological effects of forest-related visual, olfactory, and combined stimuli on humans: an additive combined effect. Urban For Urban Green 44:126437

33. Ehrlichman H, Bastone L (1992) Olfaction and Emotion. In: Serby MJ, Chobor KL (eds) Sci Olfaction. Springer New York, New York, pp 410-438

34. Song X, Li H, Li C, Xu J, Hu D (2016) Effects of VOCs from leaves of Acer truncatum Bunge and Cedrus deodara on human physiology and psychology. Urban For Urban Green 19:29-34

35. Tsunetsugu Y, Park B-J, Miyazaki Y (2009) Trends in research related to "Shinrin-yoku" (taking in the forest atmosphere or forest bathing) in Japan. Environ Health Prev Med 15:27

36. Chen CJ, Kumar KJS, Chen YT, Tsao NW, Chien SC, Chang ST, Chu FH, Wang SY (2015) Effect of Hinoki and Meniki essential oils on human autonomic nervous system activity and mood states. Nat Prod Commun 10:1305-1308

37. Garavaglia L, Gulich D, Defeo MM, Mailland JT, Irurzun IM (2021) The effect of age on the heart rate variability of healthy subjects. PLOS ONE 16:e0255894

38. Bai X, Li J, Zhou L, Li X (2009) Influence of the menstrual cycle on nonlinear properties of heart rate variability in young women. Am J Physiol Hear Circ Physiol 297:765-774

\section{Publisher's Note}

Springer Nature remains neutral with regard to jurisdictional claims in published maps and institutional affiliations.

\section{Submit your manuscript to a SpringerOpen ${ }^{\circ}$ journal and benefit from:}

- Convenient online submission

- Rigorous peer review

- Open access: articles freely available online

- High visibility within the field

- Retaining the copyright to your article 